\title{
Mechanical Forging Press for Progressive Working in Automatic Process
}

\author{
Zdenek Chval, Milan Cechura
}
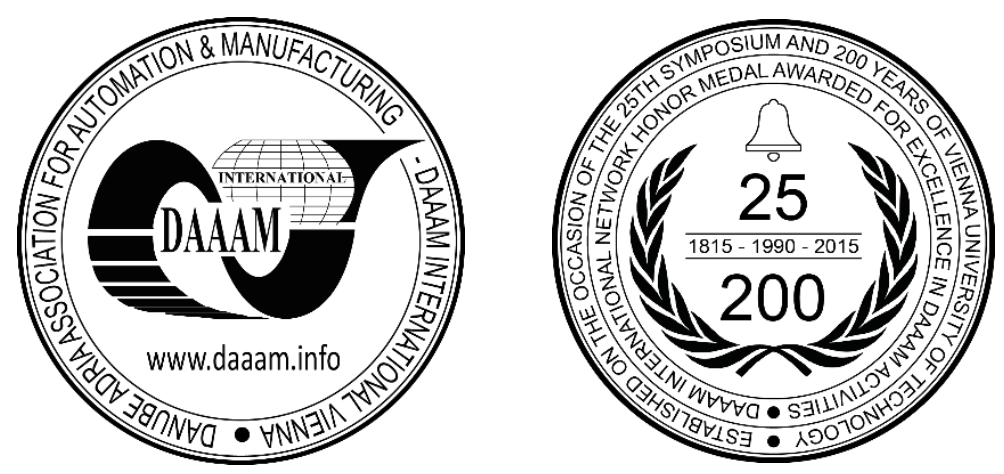

This Publication has to be referred as: Chval, Z[denek] \& Cechura, M[ilan] (2017). Mechanical Forging Press for Progressive Working in Automatic Process, Proceedings of the 28th DAAAM International Symposium, pp.0367-0371, B. Katalinic (Ed.), Published by DAAAM International, ISBN 978-3-902734-11-2, ISSN 1726-9679, Vienna, Austria DOI: $10.2507 / 28$ th.daaam.proceedings.051

\begin{abstract}
This paper deals with variants of working force distribution in press dies in the working space of asymmetrical forging press with a nominal force $25 \mathrm{MN}$. The asymmetrical forging press was designed for a left-to-right forging in five dies with maximum forging force in the last die. This paper describes the possibilities the machine loading for progressive working in all dies during one working stroke. For this purpose, FEM calculations were used to determine maximum stresses and displacements in the whole structure of the forging press.
\end{abstract}

Keywords: forming machine; mechanical forging press; structural FEM analysis; press frame

\section{Introduction}

An asymmetric mechanical forging press was designed for progressive working in five dies with a maximal force 25 $\mathrm{MN}$ in last position (with maximal eccentricity).

This design solution was motivated mainly by the need for automation and mechanization. This need is resulting in one direction forging - from left to right. When the forging press works at fifth (side) die with a maximal force (Figure 1 ), this press is much more accurate comparing to a conventional press.

The press can also be used for forging in a conventional manner if the recommended forces shown in Fig. 1 are not exceeded. In this case, the maximum force at central die position is up to $30 \mathrm{MN}$.

Precision of the forgings in the central die position of forging on an asymmetrical press does not achieve the accuracy of the classical construction. This design $[1,2]$ is also applicable to a wide range of other technological operations. 


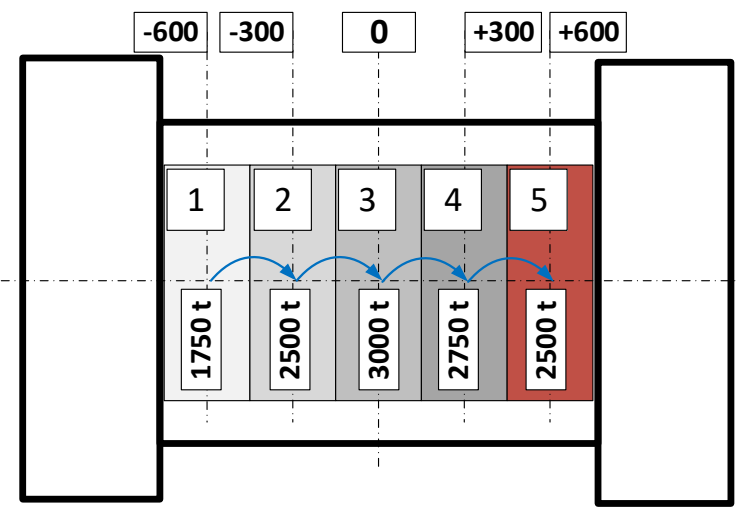

Fig. 1. Maximum work force for each die during the forging in one die [1,2].

\section{Analysis of the force distribution in the dies of multi-impression die}

Current publications on an asymmetric forging press were focused on the ability of the press to work with maximum work force at the maximum possible eccentricity of the press. The design of the frame and all other components of the crank mechanism was made with respect to this requirement $[6,7]$.

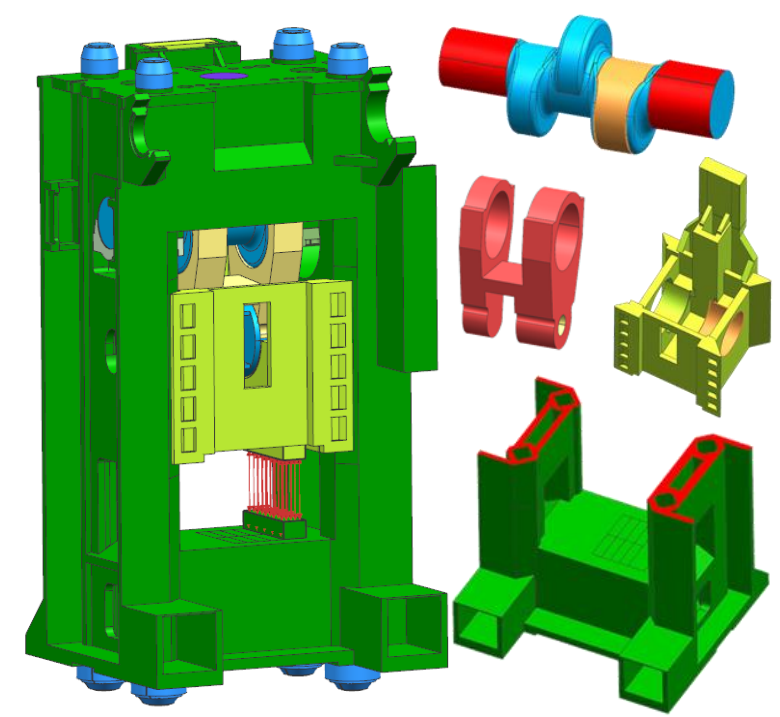

Fig. 2. An asymmetrical forging press with a working force $25 \mathrm{MN}[1,2]$.

The next step was to analyse possible variants of the working force distribution in the multi-impression die during one stroke of the machine. The variants are based on the results of the distribution of stress in the press stand from the proposed load forces. The following table shows the proposed forces distribution for which the asymmetrical press is sufficiently dimensioned.

\begin{tabular}{|c|c|c|c|c|c|c|}
\hline & \multicolumn{5}{|c|}{ POSITION OF DIE } \\
\hline & & 1 & 2 & 3 & 4 & 5 \\
\hline & & \multicolumn{5}{|c|}{ FORGING FORCE (MN) } \\
\hline \multirow{5}{*}{ 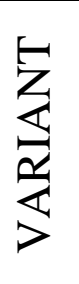 } & A & 4 & 6 & 7 & 9 & 4 \\
\hline & $\mathrm{B}$ & 3,5 & 5 & 8 & 10 & 3,5 \\
\hline & $\mathrm{C}$ & 8 & 5 & 10 & 3,5 & 3,5 \\
\hline & $\mathrm{D}$ & 3,5 & 3,5 & 5 & 8 & 10 \\
\hline & $\mathrm{E}$ & 0 & 10 & 5 & 10 & 0 \\
\hline
\end{tabular}

Table 1. Variants of the forcing force distribution in the multi-impression die during one stroke. 
The stress was evaluated for individual working force distributions (Fig.3) [3, 4, 5]. The simulation was performed using the Siemens NX 11 software $[8,9]$. The stress do not exceed the allowable values and the forging press can therefore be used for all proposed variants of forging forces.

It can be seen in the figures that the largest stress is located under the anchor nut on the right side and below the work table near the anchors. A similar stress distribution in all these cases suggests that the proposed force distribution variants have been performed correctly.

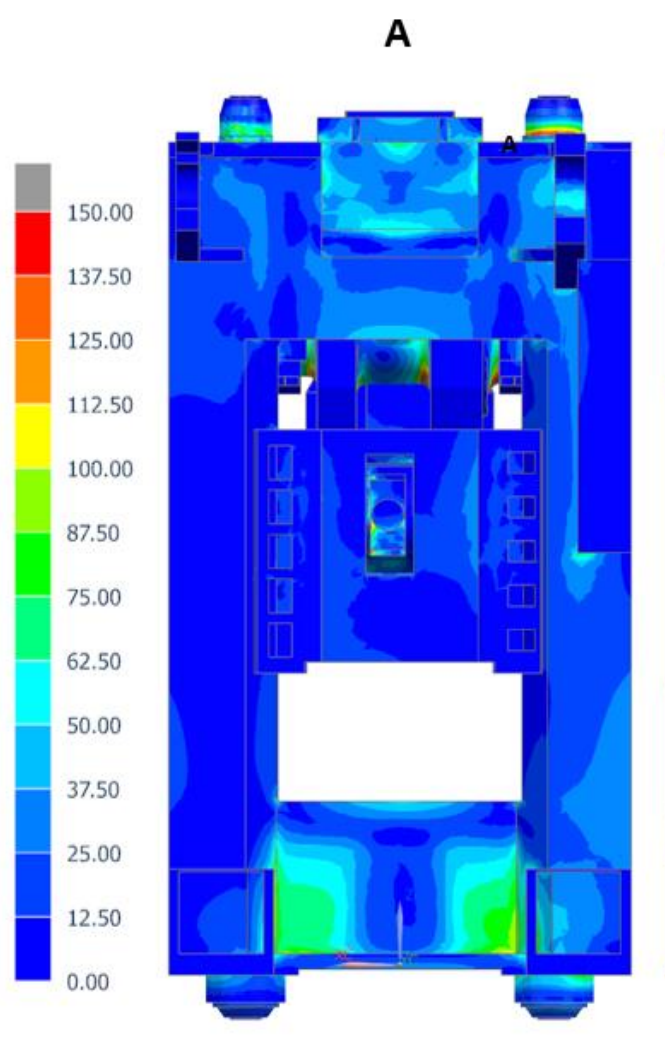

D

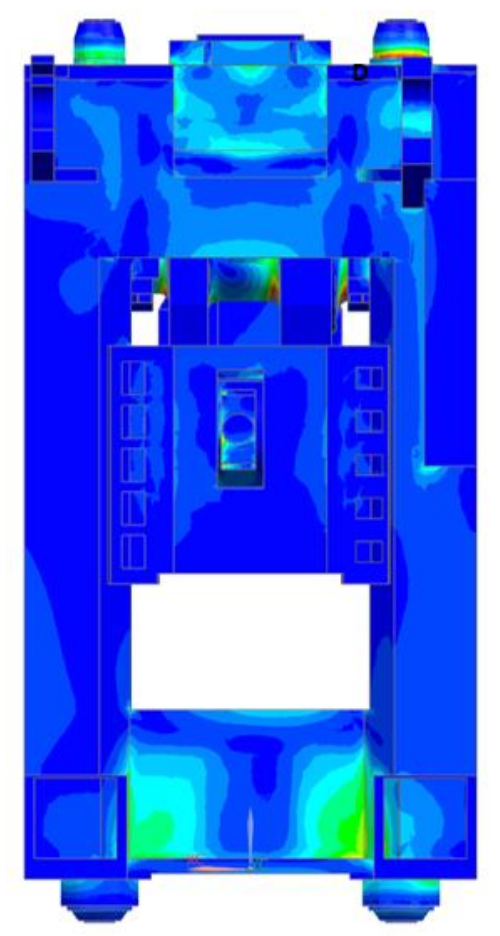

B

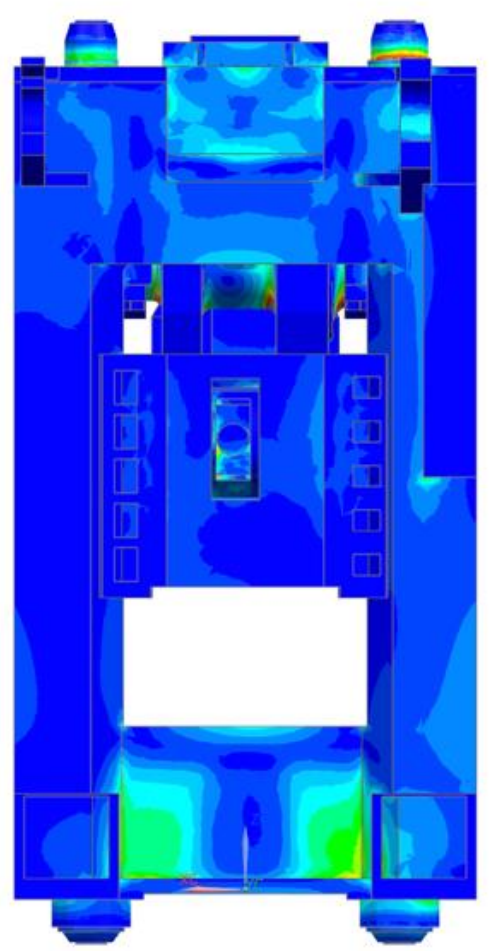

C

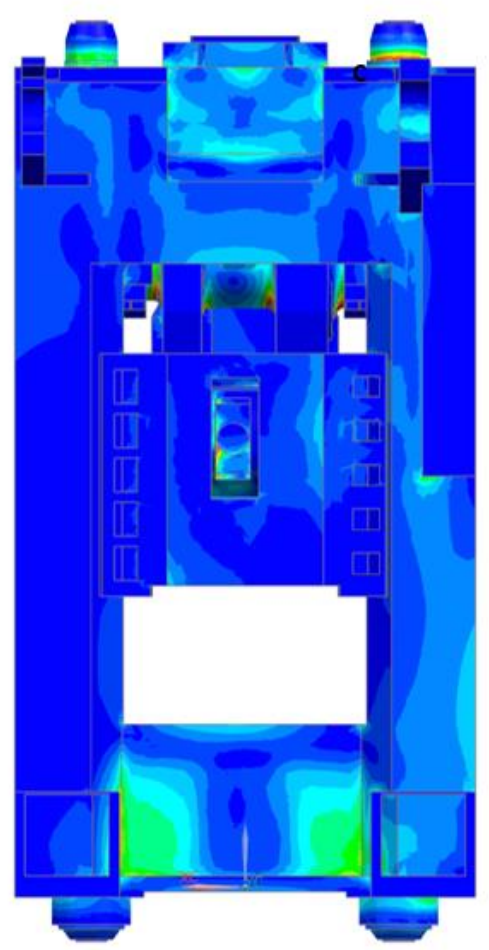

E

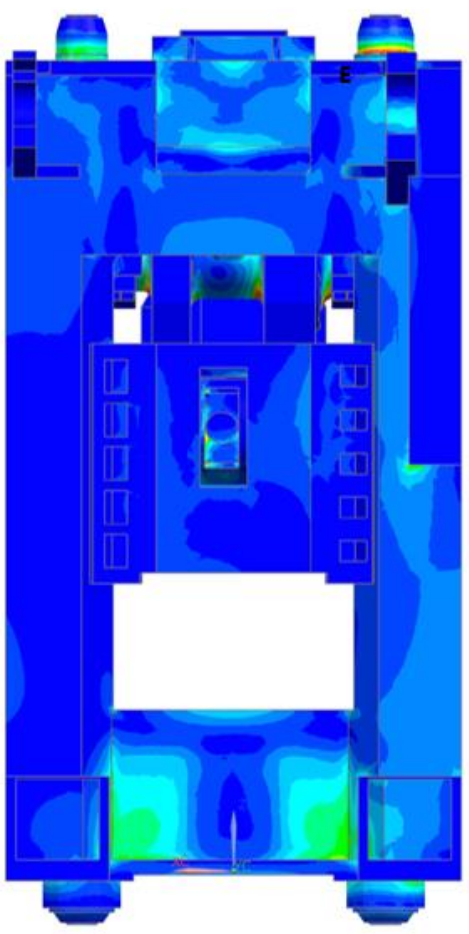

Fig. 3. Distribution of stresses on the forging press during one according to Table 1. 


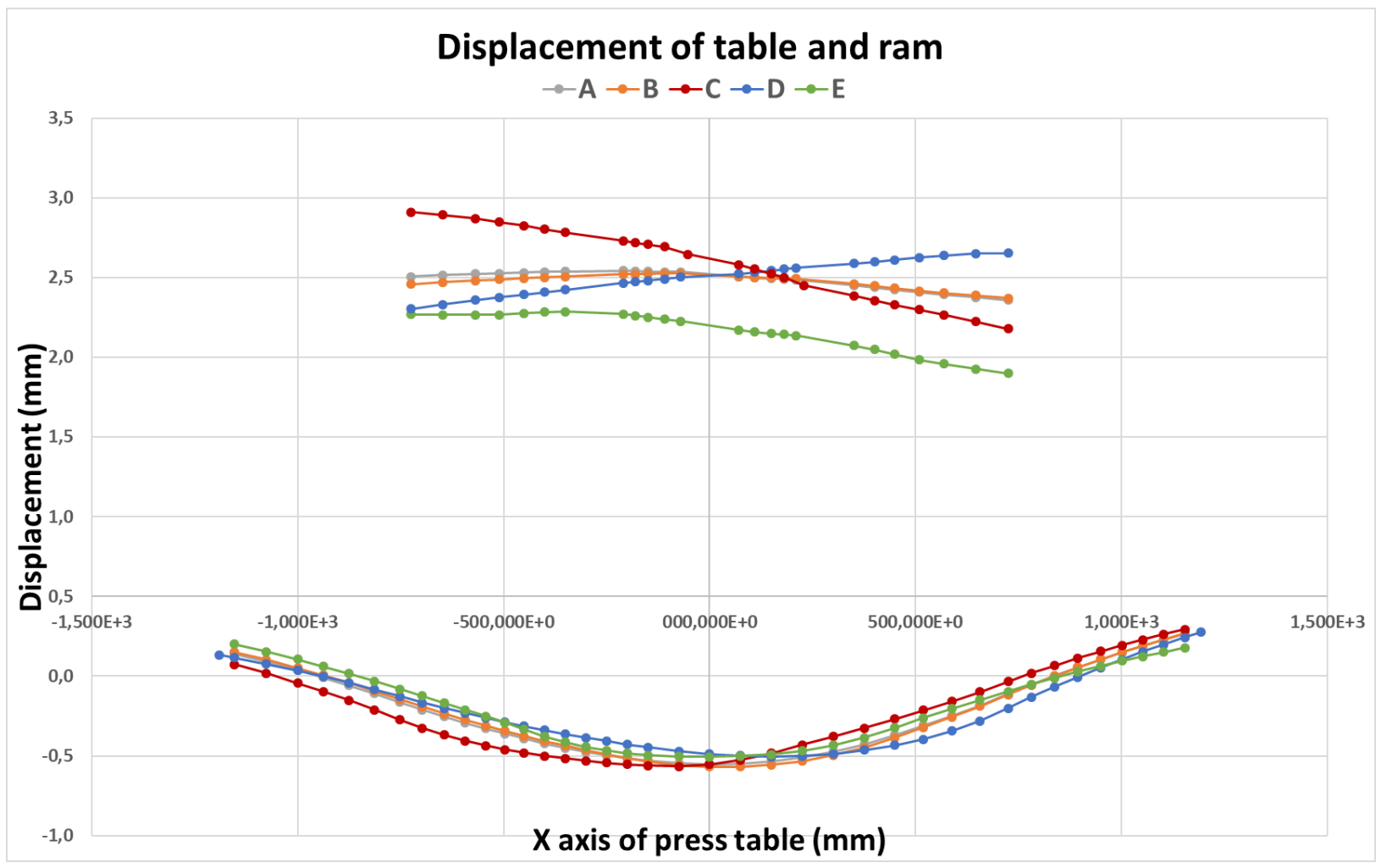

Fig. 4. Displacement of table (down) and ram (up) (mm)

For each variation of the forces distribution, the displacement of the work table and the ram was evaluated. It can be seen from Fig. 4 that the symmetrical loading of the press (variant E) results in a asymmetrical displacement of the table and the ram. Because of this, an asymmetrical press during a centric forging does not achieve such precision as a conventional forging press.

The proposed variants of the recommended load on the press work table can be modified as necessary so that the deformation of the table and ram is projected as little as possible in the final product. This is done by analyzing the curves shown in Figure 4.

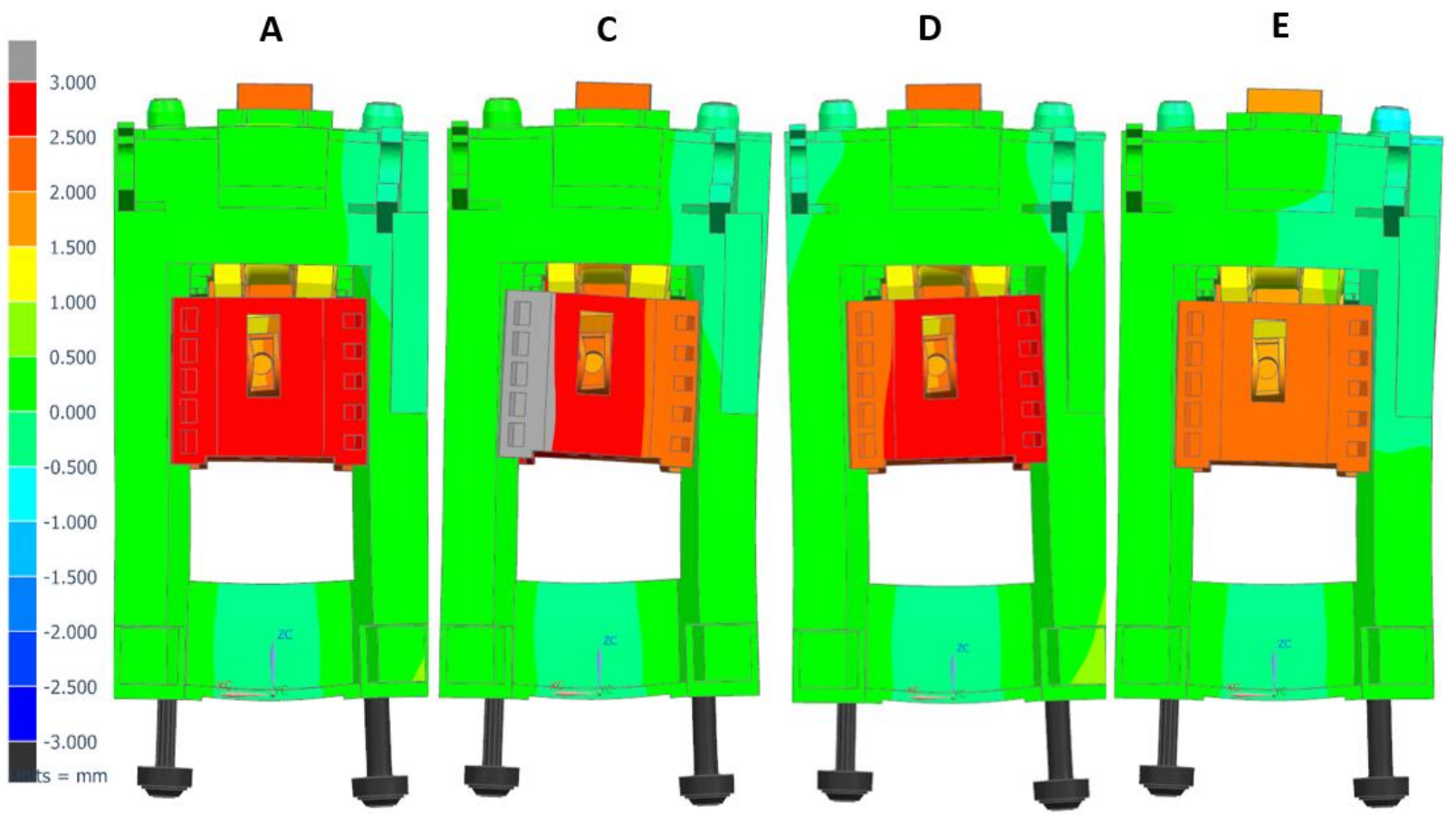

Fig. 5. Displacement of forging press in vertical direction. 


\section{Conclusion}

Results described above were obtained with increasing of weight from 164t to 169t. The weight is considering frame, anchors, crankshaft, connecting rods and ram.

This solution is not single-purpose machine and can be used for various technological operations, when sorting operations from left to right - especially for automatic process. The press is primarily designed to place the maximum force centric or eccentric to the right of the center. As shown in Figures 4 and 5, when a dominant force is placed to the left side of the press table, a larger overall displacement occurs, a larger tilting of the die and it is resulting in lower forging accuracy. This results from the comparison of the curves $C$ and $D$ at the table and the ram of the press.

In the case of the forging in central position, it is more advantageous to use the press of a classic concept due to the tilting and machine precision. This is illustrated by the curves of variant E. Although it is a central forging, there is an asymmetrical displacement of the table and ram (see Figure 4).

\section{Acknowledgments}

This article was done by financial support of TA ČR - project TE01020075.

\section{References}

[1] Chval Z., Cechura, M. (2016). Design of mechanical forging press with maximal force in side cavity, MM Science Journal, November 2016, pp. 1358-1361, ISSN:1803-1269

[2] Chval, Z., Cechura M. (2015). Monitoring Extremly Stressed Points on Stands of Forging Presses, 25th DAAAM International Symposium on Intelligent Manufacturing and Automation 2014, Procedia Engineering, 2015 , p. 841 846.

[3] Hawryluk, M., Kaszuba, M., Gronostajski, Z., Sadowski, P. (2016). Systems of supervision and analysis of industrial forging processes, Eksploatacja i Niezawodnosc, 18 (3), pp. 315-324.

[4] Hawryluk, M., Ziemba, J. (2017). Possibilities of application measurement techniques in hot die forging processes, Measurement: Journal of the International Measurement Confederation 110, pp. 284-295, ISSN:0263-2241

[5] Hawryluk, M. (2016). Review of selected methods of increasing the life of forging tools in hot die forging processes, Archives of Civil and Mechanical Engineering, 16 (4), pp. 845-866.

[6] Chval Z., Cechura, M., Raz, K. (2015). Analysis of stress distribution in the forging press, Annals of DAAAM and Proceedings of the International DAAAM Symposium, 2015-January, pp. 488-493

[7] Chval Z., Cechura, M. (2014). Optimization of power transmission on mechanical forging presses, Procedia Engineering 69, pp. 890-896, ISSN:1877-7058

[8] Raz, K.; Cechura, M., Chval, Z. (2015). Upper Crossbeam of Free Forging Press Optimization in Order to Improve Mechanical Properties and Durability, 26th DAAAM International Symposium on Intelligent Manufacturing and Automation, DAAAM 2015-January, pp. 524-529

[9] Zahalka, M.; Stanek, J., Raz, K. (2015) Cross Wedge Rolling and Forging Rolls as Additional Devices in Closed Die Forging, 26th DAAAM International Symposium on Intelligent Manufacturing and Automation, DAAAM 2015 - January, pp. 530-535 